\title{
Risk factors for ventricular tachycardia in acute ST-elevated myocardial infarction patients of a tertiary care hospital of Peshawar
}

Inam Ullah, Ashfaq Ahmad Shah Bukhari, Mehwish Durrani, Zulfania Khan, Saman Tauqir, Babur Farid, Muhammad Farooq Khan

\section{Submitted}

October 05, 2020

Accepted

November 10, 2020

\section{Author Information}

Dr. Inam Ullah

Internee, Hayatabad Medical Complex, Khyber Medical

University, Peshawar,

Pakistan.

From: Rehman Medical College, Peshawar, Khyber Pakhtunkhwa, Pakistan.

Dr. Ashfaq Ahmad Shah Bukhari

Associate Professor, Department of Physiology. (Corresponding Author)

Email:

drashfaqbukhari@hotmail.co $\mathrm{m}$

Dr. Mehwish Durrani

Associate Professor,

Department of Biochemistry.

From: Department of

Physiology, Rehman Medical College, Peshawar, Pakistan.

Dr. Zulfania Khan

Assistant Professor

Dr. Saman Tauqir

Lecturer

Dr. Babar Farid

Lecturer

Dr. Muhammad Farooq Khan Lecturer

Citation: Ullah I, Bukhari AAS, Durrani M, Khan Z, Tauqir S, Farid B, et al. Risk factors for ventricular tachycardia in acute STelevated myocardial infarction patients of a tertiary care hospital of Peshawar. J Rehman Med Inst. 2020 OctDec;6(4):12-5.

\section{ABSTRACT}

Introduction: Ventricular arrhythmias are the most common cause of death in various ST-Elevated Myocardial Infarction (STEMI) patients and can be prevented if diagnosed and managed in time.

Objectives: To document the occurrence of ventricular tachycardia in patients with acute ST-segment elevated myocardial infarction (STEMI) admitted to a tertiary care hospital of Peshawar and to identify associated risk factors.

Materials \& Methods: A descriptive cross-sectional study consisting of 252 MI patients of 51-60 years of age, were observed for the presence of ventricular tachycardia at Lady Reading Hospital, Peshawar from September 2017 to January 2018.

Results: Hypertension was found to be the most common risk factor for ventricular tachycardia observed in 180 patients. Diabetes mellitus was the $2^{\text {nd }}$ most common risk factor present in 104 patients while smoking was found in 56 patients. The most common location of ST-Elevation MI was anterior wall myocardial infarction (30.2\%) occurring in 76 patients.

Conclusion: Ventricular tachycardia occurred in a quarter of the patients presenting with acute ST-elevated myocardial infarction, and was more common in anterior wall MI followed by extensive anterior wall MI.

Keywords: Ventricular Tachycardia; Myocardial Infarction; Diabetes Mellitus; Smoking.

The authors declared no conflict of interest. All authors contributed substantially to the planning of research, data collection, data analysis, and write-up of the article, and agreed to be accountable for all aspects of the work.

\section{INTRODUCTION}

Myocardial ischemia can occur because of high metabolic demand of cardiac tissue, less supply of nutrients and oxygen to the tissue through coronary dissemination, or both. Thrombus formation in coronary arteries and consequent occlusion compromises the inflow of oxygen and other nutrients. ${ }^{1}$ Myocardial infarction (MI) is classified based on diagnostic criteria into ST-Elevation Myocardial Infarction (STEMI) and non-STsegment Elevation Myocardial Infarction (NSTEMI) due to the ECG appearance of elevated or non-elevated ST-segment. ${ }^{2,3} \mathrm{MI}$ is the leading cause of death in the USA and other developed countries; almost 450,000 people die in the USA per year due to MI, with a survival rate of $95 \%$ in hospitalized patients. ${ }^{4}$ Identified significant risk factors for non-fatal MI in patients with STEMI and NSTEMI included sexual orientation, increasing age, high blood pressure, diabetes mellitus, dyslipidemia, tobacco use, chronic obstructive pulmonary disease and family history of atherosclerotic illness. $^{5}$

Ventricular tachycardia (VT) can occur due to coronary heart disease, aortic stenosis, cardiomyopathy or electrolyte problems and is found initially in about $7 \%$ of people having cardiac arrest. It may result in ventricular fibrillation leading to sudden death. ${ }^{6}$ It is reported that about $20 \%$ of acute myocardial infarction patients develop accelerated idioventricular rhythm. $^{7}$ It is diagnosed by using electrocardiogram (ECG), showing a heart rate of greater than 120 beats per minute and at least three wide QRS complexes in a row and then classified on the basis of duration as sustained and nonsustained. ${ }^{6}$ Non-sustained ventricular tachycardia (NSVT) is termed as a condition in which three or more consecutive ventricular ectopic beats occur at a rate faster than $100 \mathrm{bpm}$ for less than 30 seconds. ${ }^{8}$ In patients with NSTEMI acute coronary syndrome, if NSVT occurs beyond 48 hours of admission, it indicates increased risk of cardiac arrest and sudden death, especially when associated with MI. ${ }^{9}$ NSVT is a significant predictor for arrhythmic events in patients with left ventricular systolic dysfunction LVSD. ${ }^{10}$ 
Proper monitoring is necessary in continues episodes of nonsustained VT and also great attention needed for electrolyte imbalances such as potassium must be maintained above 4.5 $\mathrm{mEq} / \mathrm{L}$, magnesium level must be above $2.0 \mathrm{mEq} / \mathrm{L} .{ }^{9} \mathrm{VT}$ in which three or more than three consecutive ventricular ectopic beats occurs at a rate higher than $100 \mathrm{bpm}$ and maintain for more than $30 \mathrm{sec}$ is known as sustained VT. It may be monomorphic ventricular tachycardia or polymorphic ventricular tachycardia depending on the origin. Myocardial scar usually results in monomorphic ventricular tachycardia whereas polymorphic VT is most responsive to measures occurred against ischemia. Polymorphic VT after acute MI is associated with hospital mortality rate of $20 \% .^{11}$

\section{MATERIALS \& METHODS}

A descriptive cross-sectional study was done in Cardiology section of Lady Reading Hospital, Peshawar from September 2017 to January 2018 on 252 myocardial infarction (MI) patients who were examined and observed for Ventricular tachycardia. Patients of ages 30-80 years of both genders having STEMI were included. Patients were diagnosed based on ECG and those with ventricular tachycardia but having no acute STEMI or other cardiac diseases were excluded. All data were collected from the patients' charts in organized manner on a structured Performa. Patients presenting complaints along with background history, current medication and investigations carried out in hospital were noted. Data from ECGs were collected, and the frequencies of ventricular tachycardia were documented.

Statistical Package for Social Sciences (SPSS) version 22 was used for descriptive data analysis. Mean, frequencies \& percentages were calculated and data represented graphically (bar graph, pie charts etc.).

\section{RESULTS}

Of 252 patients, the most common age group was 51-60 years. The mean age was 55 years (range $30-80$ years.)

The most common location of STEMI was Anterior Wall Myocardial Infarction (AWMI), occurring in 76 patients; 64 patients had Extensive Anterior Wall MI (EAWMI), lateral wall MI was found in 24 patients, 8 patients had antero-lateral MI, 12 patients with posterior wall MI, 48 patients were with Inferior and 20 patient had Infero-posterior wall MI as shown in Table 1.

Table 1: Location of myocardial infarction in STEMI patients $(\mathbf{n}=\mathbf{2 5 2})$.

\begin{tabular}{|c|c|c|}
\hline Types of MI & Frequency & Percent \\
\hline Anterior wall MI & 76 & 30.2 \\
\hline Extensive-Anterior wall MI & 64 & 25.4 \\
\hline Inferior wall MI & 48 & 19.0 \\
\hline Lateral wall MI & 24 & 09.5 \\
\hline Infero-posterior wall MI & 20 & 07.9 \\
\hline Posterior wall MI & 12 & 04.8 \\
\hline Antero-lateral wall MI & 08 & 03.2 \\
\hline Total & 252 & 100.0 \\
\hline
\end{tabular}

Ventricular tachycardia was present in 64 patients out of 252 patients and 188 patients had myocardial infarction without ventricular tachycardia as shown in Figure 1.

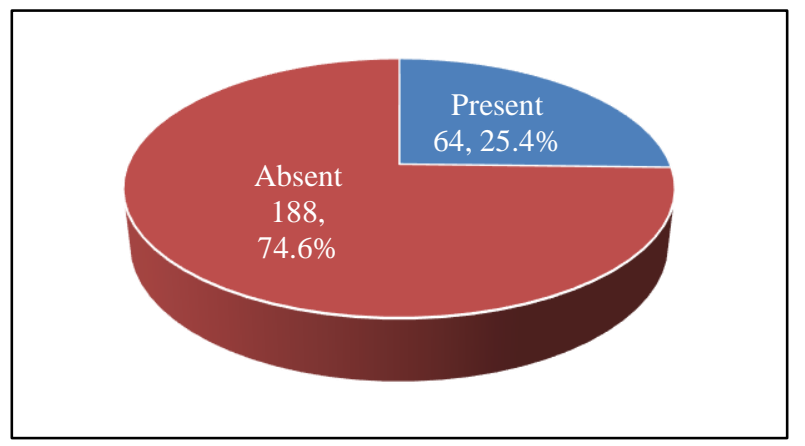

Figure 1: Frequency of Ventricular Tachycardia in STEMI patients $(\mathbf{n}=\mathbf{2 5 2})$.

Major known risk factors were hypertension, diabetes and smoking. Hypertension, the most common risk factor, was found in 180 patients; Diabetes Mellitus (DM) was present in 104 patients, while Smoking was found in 56 patients as shown in Figure 2a.

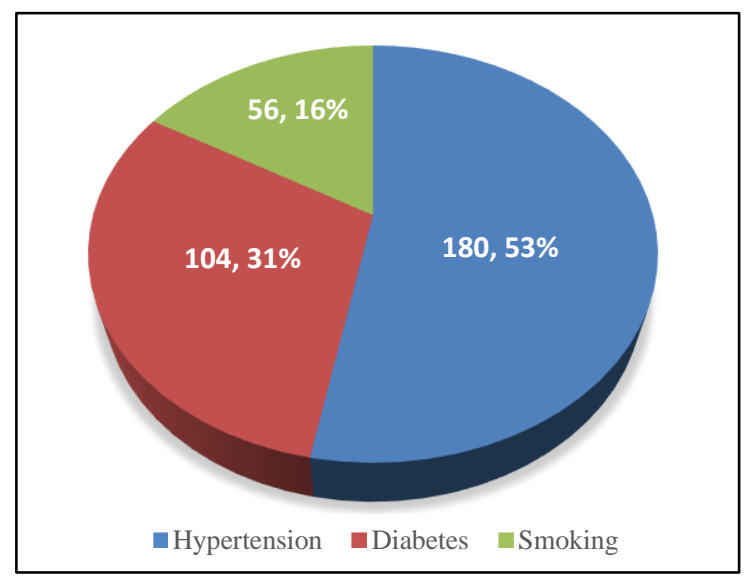

Figure 2a: Risk factors in STEMI patients $(\mathrm{n}=252)$.

Hypertension and Diabetes both were more common in males than females. In 180 Hypertensive patients, females were 68 and males were 112 while in 104 diabetic patients, females were 44 and males were 60 as shown in the Figure $2 b$.

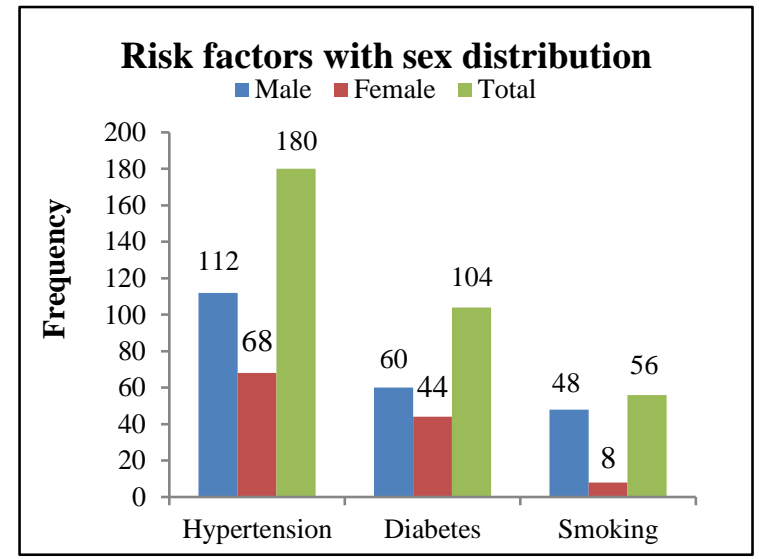

Figure 2b: Risk factor in STEMI patients with sex distribution $(\mathrm{n}=\mathbf{2 5 2})$. 
In these 64 VT patients, $52(81.25 \%)$ patients were hypertensive and $12(19.75 \%)$ were without hypertension as shown in Table 2. In 64 VT patients, $12(19.75 \%)$ patients were with diabetes mellitus and 52(81.25\%) were without diabetes mellitus.

Table 2: Hypertensive and diabetic patients with ventricular tachycardia $(n=64)$.

\begin{tabular}{|l|c|c|c|}
\hline \multirow{2}{*}{ Risk Factor } & \multicolumn{2}{|c|}{ Ventricular Tachycardia } & \multirow{2}{*}{ Total } \\
\cline { 2 - 3 } & Present & Absent & \\
\hline Hypertension & & & \\
Yes & 52 & 128 & 188 \\
No & 12 & 60 & 72 \\
\hline Diabetes Mellitus & & & \\
Yes & 12 & 92 & 104 \\
No & 52 & 96 & 148 \\
\hline
\end{tabular}

Ventricular tachycardia was present in 36(56.25\%) patients of Anterior wall MI, 12(19.75\%) patients of extensive anterior wall MI, 08(12.5\%) patients of inferior wall MI, and 04(06.25\%) patients each of Infero-posterior wall MI and anterolateral wall MI. No VT was found in posterior wall MI and lateral wall MI as shown in Table 3.

Table 3. Frequency of ventricular tachycardia in different types of STEMIs $(n=64)$.

\begin{tabular}{|c|c|c|c|}
\hline \multirow[t]{2}{*}{ Location of MI } & \multicolumn{2}{|c|}{$\begin{array}{l}\text { Ventricular } \\
\text { Tachycardia }\end{array}$} & \multirow[t]{2}{*}{ Total } \\
\hline & Present & Absent & \\
\hline Anterior wall & 36 & 40 & 76 \\
\hline Extensive anterior wall & 12 & 52 & 64 \\
\hline Inferior wall & 08 & 40 & 48 \\
\hline Infero-posterior wall & 04 & 16 & 20 \\
\hline Antero-lateral wall & 04 & 04 & 08 \\
\hline Lateral wall & 0 & 24 & 24 \\
\hline Posterior wall & 0 & 12 & 12 \\
\hline Total & 64 & 188 & 252 \\
\hline
\end{tabular}

\section{DISCUSSION}

Ventricular Arrhythmias is most common leading cause of death in various ST-Elevated MI and therefore it should be predicted and prevented as according to the situation. ${ }^{12}$ Although mortality due to these is reduced nowadays because of development of CCUs and Closed chest massages, Electrical cardio reversion and newer anti-arrhythmic drugs. The onsets of Ventricular arrhythmias (VT and VF) are relatively high in first 48 Hours of ST-Elevated myocardial infarction. ${ }^{13}$

The present study reported that mean age of total 252 patient was 55 years. Bruyne et al, also reported that the prevalence of different types of myocardial infarction in age 55 years or older are common. ${ }^{14}$ Deshpande JD et al, in their study observed that, the incidence of AMI was highest i.e. $31 \%$ in 51 to 60 years group ${ }^{15}$ which is similar to our findings. In the present study we found that there was a male predominance in the frequency of MI, with $160(63.5 \%)$ males and $92(36.5 \%)$ females having the disease. Siddique MB et al, also observed males (67\%) predominance over the females (33\%). ${ }^{16}$ Acharya LD et al, also reported similar findings in accordance with the findings of this study ${ }^{17}$ Most common risk factor for patients reported in the present study was Hypertension followed by Diabetes Mellitus (DM), and Smoking.

Based on data from the Cardiovascular Lifetime Risk Pooling Project, a study ${ }^{18}$ identified hypertension as a major risk factor in middle aged patients. The Life Time Risk (LTR) for CVD was $52.5 \%$ (95\% CI 51.3-53.7) for men and 39.9\% (38.7-41.0) for women, with Blacks having a higher LTR compared to Whites; these findings are in support of our study. It is a well-known fact that uncontrolled and prolonged elevated BP can lead to structural changes in the myocardial muscles, coronary vessels, and conductive system of the heart. ${ }^{19}$ The second major risk factor reported in our study was DM which occurred in 104 patients $(41 \%)$ of the total number of cases. Diabetes mellitus results in endothelial dysfunction and increased platelet activity resulting in atherosclerosis. ${ }^{20}$ The third risk factor that was reported in the present study was smoking. The association between cigarette smoking and heart diseases is well established fact. ${ }^{21}$

In the above analyzed results the total 252 patient of acute ST elevated MI, in which 64 (25.4\%) patients developed ventricular tachycardia in the early hour of ST Elevated MI. similar frequency of development of VT was reported by various international studies. ${ }^{12,22}$

Our study also suggests that in ST elevated acute MI the chances of patient going into VT is higher in acute anterior wall MI presenting with $36 \%$ of total VT cases as compared to the extensive anterior wall MI which was $12 \%$. Likewise, Inferior wall MI are at third position which is $8 \%$ of 64 patients. It means that the occurrences of VT are more common in acute anterior wall MI. Similar pattern of association between anatomical site of MI and VT was observed by Rathod et al, ${ }^{23}$ and Marangmei et al. ${ }^{24}$

\section{CONCLUSION}

Ventricular tachycardia occurred in a quarter of STEMI patients, most commonly in the anterior myocardial wall, having a male preference, and with hypertension as the major risk factor.

\section{REFERENCES}

1. Cotran RS, Kumar V, Robbins SL (eds): Robbins Pathologic Basis of Disease. 5th ed. Philadelphia: WB Saunders, 1994.

2. Thygesen K, Alpert JS, White HD. Joint ESC/ACCF/AHA/WHF Task Force for the Redefinition of Myocardial Infarction: Universal definition of myocardial infarction. Eur Heart J. 2007;28:2525-38.

3. Kimball JT, Killip T: Aggressive treatment of arrhythmias in acute myocardial infarction: Procedures and results. Prog Cardiovasc Dis. 1968; 10:483-504.

4. American Heart Association. Cardiovascular disease statistics. Available at https://www.heart.org/en/aboutus/heart-and-stroke-association-statistics.

5. Rapsomaniki E, Shah A, Perel P, Denaxas S, George J, Nicholas O, et al. Prognostic models for stable coronary artery disease based on electronic health record cohort of
102,023 patients. Eur Heart J. 2014 Apr; 35(13):844-52.

6. Baldzizhar A, Manuylova E, Marchenko R, Kryvalap Y, Carey MG. Ventricular tachycardias: characteristics and management. Critical Care Nursing Clinics. 2016 Sep 1;28(3):317-29.

7. Thomas DE, Jex N, Thornley AR. Ventricular arrhythmias in acute coronary syndromes-mechanisms and management. 
Continuing Cardiology Education. 2017 Mar;3(1):22-9.

8. Monserrat L, Elliott PM, Gimeno JR, Sharma S, Penas-Lado M, Mckenna W J. Non-sustained ventricular tachycardia in hypertrophic cardiomyopathy: an independent marker of sudden death risk in young patients. J Am Coll Cardiol. 2003;42(5):873-9.

9. Katritsis DG, Zareba W, Camm AJ Nonsustained ventricular tachycardia. J Am Coll Cardiol. 2012;60(20):1993-2004.

10. De Sousa MR, Morillo CA, Rabelo FT, Filho AMN, Ribeiro AL. Non-sustained ventricular tachycardia as a predictor of sudden cardiac death in patients with left ventricular dysfunction: A meta-analysis. Eur J Heart Fail. 2008 Oct;10(10);1007-14.

11. Nagarajarao HS. Complications of myocardial infarction. Arrhythmic Complications: Ventricular Arrhythmias. [webpage]. Available at:

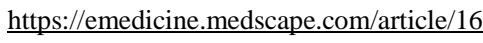
4924-overview\#a7.

12. Bhar-Amato J, Davies W, Agarwal S Ventricular arrhythmia after acute myocardial infarction: 'The Perfect Storm'. Arrhythm Electrophysiol Rev. 2017;6(3):134-9.

13. Askari AT, Shishehbor MH, Kaminski MA, Riley MJ, Hsu A, Lincoff AM, et al. The association between early ventricular arrhythmias, renin-angiotensin-aldosterone system antagonism, and mortality in patients with ST-segment-elevation myocardial infarction: Insights from Global Use of Strategies to Open coronary arteries (GUSTO) V. Am Heart J. 2009 Aug 01;1582:238-43.

14. de Bruyne MC, Mosterd A, Hoes AW, Kors JA, Kruijssen DA, van Bemmel JH, et al. Prevalence, determinants, and misclassification of myocardial infarction in the elderly. Epidemiology. 1997 Sep;8(5):495-500.

15. Deshpande JD, Dixit JV. Risk factors for acute myocardial infarction: a hospitalbased case control study. Health and Population; Perspectives and Issues. 2008 Jul;31(3):164-9.

16. Siddique MB, Fazal I, Ejaz A, Awan ZI. Frequencies and patterns of arrythmias in anterior and inferior myocardial infarction. Pak Armed Forces Medical Journal. 2009;59(4):450-4.

17. Faizal P, Acharya LD, Padmakumar R. Evaluation of risk factors and in-hospital outcomes in patients with coronary artery disease in a tertiary care teaching hospital. International Journal of PharmTech Research. 2009;1(4):1378-89.

18. Allen N, Berry JD, Ning H. Impact of blood pressure and blood pressure change during middle age on the remaining lifetime risk for cardiovascular disease: the cardiovascular lifetime risk pooling project. Circulation. 2012;125(1):37-44.

19. Paynter NP, Mazer NA, Pradhan AD. Cardiovascular risk prediction in diabetic men and women using hemoglobin A1c vs diabetes as a high-risk equivalent. Arch Intern Med. 2011;171(19):1712-1718.

20. Howard BV, Rodriguez BL, Bennett PH. Prevention conference VI: diabetes and cardiovascular disease: writing group I: epidemiology. Circulation. 2002;105(18):e132-e137.

21. Sugishi M, Faminaro T. Cigarette smoking is a major risk for coronary spasm Circulation. 1993;87:76-9.

22. Campbell RW, Murray AL, Julian DG. Ventricular arrhythmias in first 12 hours of acute myocardial infarction. Natural history study. $\mathrm{Br}$ Heart J. 1981 Oct;46(4):351-7.

23. Rathod S, Parmar P, Rathod GB, Parikh A. Study of various cardiac arrhythmias in patients of acute myocardial infarction. International Archives of Integrated Medicine. 2014 Dec;1(4):32-41.

24. Marangmei L, Singh SK, Devi KB, Raut SS, Chongtham DS, Singh KB. Profile of cardiac arrhythmia in acute myocardial infarction patients within 48 hours of admission: A hospital based study at RIMS Imphal. Journal of Medical Society. 2014; 28(3):175-8 